\title{
The Effectiveness of Acceptance and Mindfulness-Based Therapy on Physical Activity Increment and Obesity Decrement in the Patients Suffering from Heart Disease in Bandar Abbas
}

\author{
Sedigeh, Taj abadi pour ${ }^{1} \&$ Eghbal, Zareh $^{2}$ \\ ${ }^{1}$ Department of educational psychology, Bandar Abbas Branch, Islamic Azad University, Iran \\ ${ }^{2}$ Department of educational psychology, Bandar Abbas Branch, Islamic Azad University, Iran \\ Correspondence: Eghbal, Zareh, Department of educational psychology, Bandar Abbas Branch, Islamic Azad \\ University, Bandar Abbas, Iran.
}

Received: October 18, 2017 Accepted: November 10, 2017 Online Published: December 6, 2017

doi:10.5539/res.v10n1p1

URL: https://doi.org/10.5539/res.v10n1p1

\begin{abstract}
This research is aimed at determining the role of acceptance and mindfulness therapy on physical activity increment and obesity decrement in in the patients suffering from heart disease in Bandar Abbas. In terms of type, the research is applied one and in terms of research method, it is a quasi-experimental study along with a pretest-posttest with a control group. The statistical population of the research involves all the patients suffering from heart disease being overweight who had visited Bandar Abbas' hospitals during 2016-2017 and according to angiographic reports, eclipse was more than 50\% and $\mathrm{BMI} \geq 30$. Available sampling method was used in the study. The population size was 20 that 10 were assigned to experimental group and 10 to control group. The data were collected though making use of physical activity level, body mass index (BMI) questionnaire. The obtained data were analyzed using covariance analysis and SPSS software. The results showed that acceptance therapy had been effective on physical activity increment and body mass decrement of the patients suffering from heart disease. Based on the obtained results, it can be concluded that mindfulness-based therapy can be considered as a non-invasive treatment.
\end{abstract}

Keywords: mindfulness-based therapy, activity increment, body mass decrement, obesity

\section{Introduction}

Obesity is a chronic disease or disorder that its prevalence has increased in the United States and the other western countries so that obesity increases the danger and risk of heart disease, diabetes, and liver problems. Obesity mechanism originates from our body's inclination towards storing energy in the form of fat and its root goes back to very far ancestors of human. In the current modern life, with the availability of telephone and even online food orders that an individual does not even bother himself for taking the food, the accessibility to food has become convenient and permanent. Accordingly, late or hunger day hardly ever happens, and saving excess energy on our daily needs has created obesity. The issue of obesity is increasing not only in high-income countries but also this process is in the same manner in the urban areas with low and high incomes (Namazi, Taj Abadipour, \& Mirzayi, 2017). Obesity is a chronic disease which provides the background for most of the disease particularly cardiovascular and diabetes disorders and soon it decreases individuals' work capacity and ability and makes them vulnerable with regard to most of the disease. The consequences that obesity creates, results in life duration reduction. Overweightness and obesity is among one of the most significant issues of general health in the world (Khodapanah, 2010). Inactive lifestyle is to some extent the reason behind obesity prevalence increment (Manson et al., 2004). Obesity is accompanied with a wide range of health problems including heart disease, type 2 diabetes, high blood pressure and high blood sugar and high cholesterol. Moreover, high expenses are spent on obesity people's treatment in general health area yearly, so that approximately 12 percent of the yearly budget of the United States' general health is used in treating the problems related to obesity (Fletcher \& Hayes, 2011). According to the regular reviews which have been carried out, 36.9 percent of men and 38.5 percent of women suffer from obesity (Filmint et al., 2014). It has been proven well that exercise is important for physical and mental health. The results of the researches show that regular physical activities are beneficial and effective for all and inactive lifestyle results in early death rate increment (Fletcher \& Hayes, 2011). Accordingly, it seems that the best way with regard to weight reduction and health maintenance is increasing physical activities among individuals. 
For increasing physical activity and decreasing obesity and body weight, there are sever treatments that three of them are investigated here:

1- Surgical treatment: this method is so aggressive that it is only recommended for the patients suffering from high overweight. Of course, this method has many risks and disadvantages that most of the therapists make attempt to use it as the last resort (Cooper Fairburn, 2001).

2- Drug Therapy: This method is appropriate for the patients who commit to treatment and drug which results in 5-10 percent weight loss. Of course, permanent use of the drugs is impossible due to the dangerous consequences (Beaujar \& James, 1998).

3- Psychological treatment: These types of treatments have been created for the first time since 1960 with forms of moral treatments (Fosser, Touretteberg \& Levitt, 1992), and after that, many other treatments have been created. Among the recent psychological treatments which have attracted many people nowadays and are used in obesity treatment is cognitive behavioral and mindfulness therapy. Included among the effective treatments for overweight people who start eating in response to their feelings and reflections is acceptance and commitment therapy (Forman, Boether, Hoffman, and Herbert, 2009). From acceptance and commitment therapy's perspective, people consider most of their feelings, excitements, and inner thoughts as annoying; therefore, they make an attempt to change or avoid them and acceptance and commitment therapy is aimed at preventing avoidance by helping to accept and sense commitment.

Growing interest has been created with regard to mindfulness-based therapy about expansion of behaviors related to balanced body weight maintenance and reducing obesity like physical activities (Robert \& Danone, 2010). Reducing mindfulness stress is a referential-based systematic perspective which educates the mind-meditation and the ability to respond subtly to experiences which can result in emotional disorder or incompatible behavior. Among the incompatible behaviors, it can be referred to gourmet. Included among the other proposed treatments with regard to eating disorder treatments of adults, is mindfulness therapy (Ahadi, Razavi, \& Saramiforoushan, 2015). Recently, mindfulness-based therapy has been used widely in curing obesity and eating behaviors (Camilleri, Méjean, Bellisle, Hercberg \& Péneau, 2015) that one of its significant and essential concepts is purposeful focus. Purposeful focus has rarely been investigated in epidemiological studies (Camilleri et al., 2015); but, the studies reveal that there is a negative relationship between purposeful focus and body weight increase (Camilleri et al., 2015). Generally, some of the particular mental and behavioral mechanisms along with purposeful focus can be effective in the risk of cardiovascular disease and obesity treatment. The probable effective mechanisms include craving (for instance, for delicious food and passive activities), controlling emotions (for instance, an individual's feelings of effectiveness in achieving the goals of diabetes prevention, such as diet or physical activity, and adherence to the diet) and being aware of the present time's experiences (for instance, being aware of body with regard to use of some particular food and involving in physical activity) and feeling manner (Eric B, 2016).

Based on Bieber, Fletcher and Hayes' (2011) investigations, making use of mindfulness-based therapy has been reported effective in eating disorder treatment. In a study carried out by Mousaviyan and Moradi, Mirzayi, Shidfar, Mahmoudi and Taheri (2010) entitled the effectiveness of mindfulness-based therapy in body weight reduction and obesity, reach to the conclusion that mindfulness-based therapy has been effective in body weight reduction and obesity.

In a research which was done on patients having eating disorder by Azari, Fata, and Poursharif (2013), in a comparison between psychological and mindfulness-based therapy, they announced that there is a significant difference between these two treatment methods in the patients suffering from eating disorder with weight loss. Very briefly put, the goal of this research is investigating the effectiveness of mindfulness-based therapy in physical activity increment as well as body weight decrement of patients suffering from heart disease. Therefore, this research is aimed to answer the question that does acceptance and mindfulness-based therapy affect physical activity increment and body weight decrement in the patients suffering from heart disease in Bandar Abbas?

\section{Methodology}

The present study in a quasi-experimental study in terms of research along with pre-test, post-test and control group. The statistical population of this research involves all the patients suffering from heart disease as well as being overweight who have visited Bandar Abbas' hospitals during 2016-2017 and based on the angiographic repots, they have eclipse more than 50 percent and $\mathrm{BMI} \geq 30$. Available sampling method was used in the study and among 20 individuals, 10 were assigned randomly to experimental and 10 to control group. For data analysis, covariance analysis method was used.

Tools

Body Mass Index (BMI): Body mass index is calculated through dividing body weight (kilogram) into squared height (meter). Body weight will be measured using digital scale having $100 \mathrm{~g}$ sensitivity and height will be calculated using 
non-expandable strip with a precision of $1 \mathrm{~cm}$.

Physical activity level questionnaire (CHAMPS): The questionnaire has been created by Stewart et al. (2001), which evaluates physical activity in 4 levels of inactivity, low intensity physical activity, moderate physical activity, and high intensity physical activity and it involves the activities which have been done by the individual during a week. The intensity of the physical activity in CHAMPS questionnaire is calculated through MET which is a unit for estimating metabolic costs in physical activity. According to investigations, the face validity of the questionnaire is 96 percent, internal consistency of components is 0.61 and content validity equals 0.79 .

Mindfulness based therapy's schedule ( 8 sessions): The schedule involves 8 sessions and its time is changeable dependent on the volume and structure of the class. Sessions' presentation planning is based on Kabat-Zinn treatment plan with the aim of reducing stress and interventions with regard to nutrition and physical activity. This education encompasses main exercises (checking, sitting, eating, and walking) and sub-exercises (controlling attention, being in the moment, and selecting answers to daily happenings). In addition, classroom exercises are performed in order to increase consciousness, artistic raiders and verbal communication. Besides, home exercises are encouraged for practicing and deepening classroom education. The participants will receive a notebook, including self-contained leaflets and sheets.

Table 1: The headings and the goals of mindfulness-based therapy

\begin{tabular}{|c|c|}
\hline $\begin{array}{l}\text { First Session } \\
\text { Automatic Pilot }\end{array}$ & $\begin{array}{l}\text { 1.Mindfulness exercise/ ever silent place, 2. Creating basic rules, } \\
\text { 3.Presentation of mindfulness-based therapy experiences based on eating (eating } \\
\text { experience considering mindfulness) }\end{array}$ \\
\hline $\begin{array}{l}\text { Second session } \\
\text { More concentration on } \\
\text { mental whisperings } \\
\text { (confronting obstacles): }\end{array}$ & $\begin{array}{l}\text { 1.Investigation with main and sub-exercises, 2.Discussion over the way of scheduling time } \\
\text { for home exercises, 3.Payong attention to the amount which we are in the past or future, } 4 \text {. } \\
\text { Eating-based treatment (focus on emotions and thoughts) in relation with eating }\end{array}$ \\
\hline $\begin{array}{l}\text { Third session } \\
\text { The presence of the mind } \\
\text { of the breath }\end{array}$ & $\begin{array}{l}\text { 1. 1. Continuing deepening the experiences of the main exercises and sub-exercises, } 2 \text {. } \\
\text { Creating the capacity to observe your thoughts and emotions, 3. presence in the body, } 4 \text {. } \\
\text { Mindfulness-based therapy (signs of hunger and fullness) }\end{array}$ \\
\hline $\begin{array}{l}\text { Fourth session } \\
\text { Remaining in the present } \\
\text { time ( prevention from } \\
\text { stress severity and } \\
\text { durability) }\end{array}$ & $\begin{array}{l}\text { 1. Checking the thoughts and emotions of unpleasant experiences, } \\
\text { 2. Checking perception, } \\
\text { 3. Suggestion of yoga as a way to practice mindfulness, } \\
\text { 4. Eating treatment (food history). }\end{array}$ \\
\hline $\begin{array}{l}\text { Fifth session } \\
\text { Permission/ presence } \\
\text { document }\end{array}$ & $\begin{array}{l}\text { 1. Investigating how to resist and how to request situations, } 2 \text {. Making ourselves or others } \\
\text { bothered in a different way, } 3 \text {. Investigating how ridiculous mind is usually untrue, } \\
\text { negative, or seeks trouble; } 4 \text {. Creating emotional stability or the ability to be aware of } \\
\text { feelings without resistance or excess, } 5 \text {. Eating-based treatment (the influence of unpleasant } \\
\text { happenings) }\end{array}$ \\
\hline $\begin{array}{l}\text { Sixth session } \\
\text { The thoughts are not } \\
\text { realities. }\end{array}$ & $\begin{array}{l}\text { 1.Increasing the capacity of observing thoughts and emotions, 2.Creating the capacity } \\
\text { response instead of reaction, 3.Eating-based treatment (Purchase with Mindfulness) }\end{array}$ \\
\hline $\begin{array}{l}\text { Seventh session } \\
\text { How to take care of } \\
\text { yourself in the best way? }\end{array}$ & $\begin{array}{l}\text { 1. Mindfulness application in problematic communications, 2.Continuing creation of } \\
\text { capacity of response till reactivity, 3. Initiation of kindness exercise, 4.Mindulness } \\
\text { treatment (behavior transition) }\end{array}$ \\
\hline $\begin{array}{l}\text { Eighth session } \\
\text { Making use of what you } \\
\text { have acquired for } \\
\text { resisting against next } \\
\text { stressed manners: }\end{array}$ & $\begin{array}{l}\text { 1. Creating the capacity to send and receive love and kindness, } 2 \text {. Would you like to make } \\
\text { use of mindfulness in your life? How? Repetition of the available instructions }\end{array}$ \\
\hline
\end{tabular}




\section{Findings}

Table 4-1. shows the frequency of participants' ages

\begin{tabular}{|l|ccc|}
\hline Index variable & \multicolumn{3}{|c|}{ concentration percentage percentage frequency } \\
\hline 40 years old & 4 & 13.3 & 13.3 \\
\hline 50 Years old & 7 & 23.3 & 36.3 \\
\hline more than 50 & 9 & 63.3 & 100 \\
\hline total & 20 & & 100 \\
\hline
\end{tabular}

Table 4-4. Investigating the interaction between pre-test scores (auxiliary random variable) and physical activity and body mass (independent variable)

\begin{tabular}{|c|c|c|c|c|c|}
\hline change source & $\begin{array}{ll}\text { sum } & \text { of } \\
\text { squares }\end{array}$ & df & $\begin{array}{l}\text { mean } \\
\text { squares }\end{array}$ & $\mathbf{F}$ & Sig. \\
\hline correlated model & $234 / 815$ & 5 & $428 / 09$ & $84 / 14$ & $0 / 000$ \\
\hline coordinates axis' width & $101 / 228$ & 1 & $101 / 228$ & $4 / 353$ & $0 / 064$ \\
\hline group & $83 / 591$ & 2 & $41 / 245$ & $1 / 550$ & $0 / 024$ \\
\hline Pretest & $2651 / 244$ & 1 & $2651 / 244$ & $87 / 900$ & $0 / 000$ \\
\hline pretest group & $46 / 322$ & 2 & $23 / 161$ & $0 / 547$ & $0 / 320$ \\
\hline errors & $2530 / 896$ & 57 & $30 / 162$ & & \\
\hline total & $184850 / 744$ & 30 & & & \\
\hline Total correlation & $5860 / 744$ & 29 & & & \\
\hline
\end{tabular}

As it is clear from table 4-4, the interaction between the pretest group and scores is not statistically significant ( $\mathrm{p}>0.05$, $\mathrm{F}=0.547$ ). Therefore, the homogeneity hypothesis of regression slopes is accepted and there is a linear relationship between the pretest and posttest scores. Moreover, examining of the distribution chart of the scores of auxiliary random variable (pretest scores) and dependent variable (posttest scores) showed that there is a linear relationship between these two variables. Accordingly, the covariance analysis test can be performed.

At first, an analysis of the assumption of equality of variance errors was performed using the Levene's Test of Equality of Error Variances and also the study of normal distribution of scores using Kolmogorov-Smirnov test. Results are shown in the following two tables. 
Table 4-5. Results of the Levene's Test of Equality of Error Variances

\begin{tabular}{|l|l|l|l|}
\hline F & Df1 & Df2 & Sig. \\
\hline $0 / 357$ & 2 & 67 & $0 / 714$ \\
\hline
\end{tabular}

As it is observed in table 4-5, the absence of significant difference $p>0.05$, is indicator of the point that error variance is equal among all the group's variable levels. Moreover, through observing table 4-5 and considering the obtained significant difference level, it can be concluded that variables have normal distribution.

Hypothesis 1: Mindfulness acceptance-based therapy has a significant effect on patients' physical activity increment.

The mentioned data in table 4-5 is indicator of the point that after balancing the scores of the pretest scores, the difference is statistically significant among experimental and control group concerning physical activity ( $<<0.05, F=17.67$ ). It implies that mindfulness base therapy has been effective in patients' physical activity that through considering ETA coefficient of the parabola, it can be indicated that the effectiveness rate of this education is 0.61 .

Table 4-6. The results of covariance analysis scores of posttest of physical activity variable

\begin{tabular}{|l|l|l|l|l|l|l|}
\hline change source & Squares sum & df & Squares mean & F & Sig. & Parabola's ETA coefficient \\
\hline pretest & $3214 / 14$ & 1 & $3214 / 14$ & $14 / 83$ & $0 / 000$ & $0 / 970$ \\
\hline groups & $784 / 412$ & 1 & $799 / 321$ & $17 / 67$ & $0 / 005$ & $0 / 61$ \\
\hline
\end{tabular}

Hypothesis 2: Mindfulness acceptance-based therapy has significant effect on body mass decrement in patients suffering from heart disease.

Table4-7. the results of the posttest scores of covariance analysis of body mass variable

\begin{tabular}{|l|l|l|l|l|l|l|}
\hline Change source & Sum of squares & df & Mean of squares & F & Sig. & Parabola's ETA coefficient \\
\hline pretest & $368 / 67$ & 1 & $368 / 67$ & $12 / 137$ & $0 / 003$ & $0 / 778$ \\
\hline groups & $4631 / 906$ & 1 & $559 / 906$ & $15 / 76$ & $0 / 001$ & $0 / 31$ \\
\hline
\end{tabular}

As it is shown in 4-7 table, after balancing pretest scores, the difference between scores of experimental and control group in body mass is not significant $(\mathrm{p}<0.005, \mathrm{~F}=15 / 76)$. This implies that teaching mindfulness acceptance-based therapy has been effective in body mass reduction in the patients suffering from heart disease that by considering parabola's ETA coefficient, it can be indicated that the effectiveness rate of this education is 0.31 . 


\section{Discussion and Conclusion}

First hypothesis testing demonstrated that mindfulness acceptance-based therapy has significant effect on physical activity increment in the patients suffering from heart disease. This finding is in line with the findings of researches done by Khodapanah (2010), Hut, Paradix and Lidox (2004), Matson et al., (2004), Fletcher and Hayes (2011), Filment et al., (2014).

Growing interest has been created concerning mindfulness-based therapy with regard to the behaviors related to balanced body weight maintenance and reducing obesity such as physical activity (Robert \& Dalton, 2010). Based on the researches of Bieber, Fletcher and Hayes (2011), making use of mindfulness-based therapy has been reported as effective in eating disorder treatment. Investigations of Mousaviyan et al., (2010) titled the effectiveness of mindfulness based therapy in body weight and obesity reduction, reached to the conclusion that mindfulness-based therapy has been effective in body weight and obesity reduction.

In interpreting these findings, it can be indicated that physical activity is one of the major and main components in mental and physical health. On the other hand, the effects of physical activity, such as exercise, have been proven. Obstacles which can be considered for physical activity are fear of inability to continue, persistence, fear of judgment of others, etc. that acceptance-based therapy increases individual's accepting rate and commitment which in turn increases physical activity and continuity of exercise, which results in decrease in overweight; moreover, patients from heart disease sometimes refuse to accept their disease that acceptance therapy provides a great help in admitting the disease.

In second hypothesis testing, it was shown that mindfulness acceptance-based therapy has significant effect in body mass reduction of patients suffering from heart disease. This research is in line with the results of Hojjati, and Alipour (2014), Azari, Fata, and Pourshraif (2013), Fletcher and Hayes (2011) and Hatike, Macdanil and Becker (2011).

In interpretation of this research, it can be indicated that inclination toward exercise and physical activity results in body fat and subsequently in body mass reduction; so that, in the research carried out by Hojjati and Alipour (2014), it was revealed that the lower the physical activity, the more BMI that high BMI leads to heart disease and heart - failure increment.

\section{References}

Fouladvand, M., Farahani, H., Bagheri, F., \& Fouladvand, M. (2012). The Effectiveness of Cognitive-Behavioral Therapy in the Treatment of Girls with Obesity. Quarterly journal of research in psychological health, 6(2), 10-22.

Hassan, A., Foroushan, S., Reza, G., \& Nasim, R. (2015). Comparison of the Effectiveness of Cognitive Behavioral and Mindfulness Therapy in Weight Loss, Improving the Health and Sufficiency of Obese and Overweight Children. Doctoral dissertation Islamic Azad University of Karaj Branch. Faculty of Psychology.

Hojjati, Z., \& Alipour, V. (2014). The relationship between physical activity and anthropometric health related indicators in female university staff. Hormozgan Medical Journal, 18(2), 159-167.

Leily, N., Asghar, A., \& Maryam, G. (2015). The Effectiveness of Emotional Acceptance and Commitment Therapy in Obese Women. Knowledge and Research in Applied Neuroscience, 16th year, 2, 15-23.

Leila, N., Sedigheh, T. A., Vida, S., Mirzayi, S., \& Zahra, S. (2017). Treatment of obesity with a cognitive-minded approach. Ardebil: University of Mohaghegh Ardebil Press.

Lily, N., \& Asghar, A. (2015). The Effectiveness of Acceptance and Commitment Therapy on Body Mass Index in Women with Obesity. Psychiatric Nursing. 3(2), 11-22.

Narges, M., Alireza, M., Jafar, M., Farzad, S., Bahram, M. K., \& Fatemeh, T. (2010). Effectiveness of cognitive-based therapy on reducing obesity. Thought and Behavior (Applied Psychology), 16(4), 49-58.

Qari, P. M., Mohammadifard, N., Asgari, P., \& Naderi, Gh. (2003). The prevalence of obesity and risk factors for cardiovascular disease in Isfahan. Journal of Qazvin University of Medical Sciences and Health Services, 26, 53-64.

\section{Copyrights}

Copyright for this article is retained by the author(s), with first publication rights granted to the journal.

This is an open-access article distributed under the terms and conditions of the Creative Commons Attribution license (http://creativecommons.org/licenses/by/4.0/). 